\title{
Incidence of adverse reaction of drugs used in COVID-19 management: a retrospective, observational study
}

\author{
Jia Yin Lee ${ }^{*}$, Abby Shoon Yeun Ang, Nurdalila Mohd Ali, Li Min Ang and Azura Omar
}

\begin{abstract}
Background: An urgent need for coronavirus infectious disease (COVID-19) treatment has resulted in off-label drug use. Although previous studies had investigated the adverse drug reaction (ADR) of the medications for COVID-19 in their respective local settings, the safety profile in a Malaysian setting remains unknown. Our study aims to establish the incidence of ADR for drugs used in COVID-19 management in a Malaysian tertiary hospital.

Methods: This retrospective observational study enrolled patients started on drugs for COVID-19 in Sungai Buloh Hospital from 1 March 2020 to 31 May 2020. The clinical staging of COVID-19 patients was decided by the treating physician in accordance with the Clinical Management of Confirmed COVID-19 Case in Adults (Annex 2E). Suspected ADRs were evaluated with a trigger tool of pre-defined laboratory values or the adverse events listed in the registered product insert. Causality assessment was conducted when an ADR was suspected using the World Health Organization-Uppsala Monitoring Centre (WHO-UMC) system, and only cases classified as certain, probable and possible ADR were considered. Data analysis was completed with descriptive, univariate and multivariate analysis.
\end{abstract}

Results: The study $(N=1,080)$ identified 217 patients (20.1\%) who experienced ADR, with 246 adverse events detected. Most events were related to the gastrointestinal (43.5\%), hepatobiliary (36.2\%) and cardiac (16.3\%) systems. The most commonly suspected drugs were atazanavir (52.7\%), chloroquine (36.8\%) and lopinavir/ritonavir (34.6\%). The independent risk factors of ADR were female (adjusted odds ratio (OR): 1.53; 95\% Cl 1.06-2.20; $P=0.024$ ), diagnosis of COVID-19 stage 3 (adjusted OR: $2.58 ; 95 \% \mathrm{Cl} 1.20-5.55 ; P=0.015$ ) and stage 4 (adjusted OR: $4.17 ; 95 \% \mathrm{Cl}$ $1.79-9.73 ; P=0.001$ ), and the number of COVID-19 drugs (adjusted OR: 3.34; $95 \% \mathrm{Cl} 2.51-4.44 ; P<0.001$ ). Only 49 adverse events (19.9\%) were manually reported by healthcare professionals, with hyperbilirubinaemia (65.3\%) and QT prolongation (28.6\%) most frequently reported.

Conclusion: Medications used in COVID-19 management had resulted in one in five patients experiencing ADR. Our study has provided an overview on incidence of ADR for off-label use of medications used in COVID-19 management, which suggests a similar safety profile when used for FDA-approved indications.

Keywords: Adverse drug reactions, Clinical pharmacy, Drug safety, Drug monitoring, Pharmaceutical care

Communicated by Zaheer Babar, University of Huddersfield, UK

*Correspondence: joannelee415@gmail.com

Department of Pharmacy, Sungai Buloh Hospital, Ministry of Health

Malaysia, Sungai Buloh, Selangor, Malaysia

\section{Introduction}

The World Health Organization (WHO) declared the novel coronavirus disease 2019 (COVID-19) to be an international public health crisis on 30 January 2020 [1]. Drugs that were previously used to treat severe acute respiratory syndrome (SARS) and Middle-East respiratory syndrome (MERS), such as chloroquine, 
hydroxychloroquine and interferon beta- $1 \mathrm{~b}$, are now potential candidates to treat COVID-19. The rationale behind repurposing these agents is mostly based on the similar genetic proximity that these viruses share, resulting in an off-label use of these medicines [2].

Numerous clinical studies are currently being conducted globally to investigate the effectiveness of potential drug therapies for COVID-19. Although the current focus is mainly investigating the efficacy of drugs for COVID-19 treatment, priority should also be given to ensure medication safety due to a $44 \%$ increase in risk associated with off-label drug use [3].

Despite adverse drug reaction (ADR) being documented with registered indications, the safety profile of repurposed COVID-19 medications remains largely unknown with limited evidence. A multicentre, observational study on chloroquine use in COVID-19 patients $(N=197)$ concluded that well-established side effects occurred in $26.9 \%$ of chloroquine group, i.e. dizziness (10.2\%) and nausea (9.1\%) [4]. Meanwhile, a French study by Gerard et al. [5] found that among 120 cardiac events due to drugs for COVID-19 management (hydroxychloroquine, chloroquine, lopinavir-ritonavir and azithromycin), 36.6\% of cardiac events were associated with serious QT prolongation of QTc value $>500 \mathrm{~ms}$. An active monitoring study in China with COVID-19 patients on treatment $(N=217)$ recorded an ADR rate of $37.8 \%$, with the main complaints including gastrointestinal disorders (23\%) and liver system disorders (13.8\%) [6]. In view of the scarcity of ADR reports from drugs for COVID-19 management, pharmacovigilance represents an important role in safety surveillance activity.

The National Pharmaceutical Regulatory Agency (NPRA) of Malaysia encourages ADR monitoring and reporting to determine the incidence of ADR, to identify predisposing risk factors for ADR and to maintain a national ADR database [7]. Previous studies have shown that ADR contributing factors include age, gender, multiple drug therapy, current disease, ethnic, genetic differences and pharmaceutical factors [8].

Reporting of suspected or known ADR of drugs when used in real healthcare settings can help to identify patterns and trends not found in clinical trials, resulting in heightened regulatory scrutiny and drug withdrawal based on risk-benefit ratio [9]. A systematic review by Hazell et al. [10] found that the reporting rate of ADR had been underwhelming, with a median of $94 \%$ underreporting rate (interquartile range 82-98\%) after reviewing spontaneous reports from hospitals and general practices across 37 studies from 12 countries. Contributions from these reports are necessary to provide timely information about the safety of these experimental COVID-19 drug therapies and to promote rational drug use.
This study aims to establish the incidence of ADR due to off-label drugs used in COVID-19 management in a local tertiary hospital setting. Secondary outcome measures are to establish the type of ADRs, to identify potential risk factors for ADR and to evaluate the reporting rate of ADR for healthcare professionals.

\section{Methods}

\section{Study design and population}

A retrospective, observational study using electronic medical records (EMRs) from Sungai Buloh Hospital, the main referral hospital for COVID-19 in Malaysia, was conducted to include data from 1 March 2020 to 31 May 2020.

The diagnosis and clinical staging of COVID-19 patients were done in accordance with the local guideline, Clinical Management of Confirmed COVID-19 Case in Adult (Annex 2E) by the Ministry of Health, Malaysia [11]. Clinical staging was updated according to patients' disease progression upon daily review (Table 1), with the highest clinical staging taken into account in this study. Patients started on medications for COVID-19 were included in the study. Children aged 12 years and below with COVID-19 were only started with symptomatic treatment, hence excluded from the study.

All patients with suspected or confirmed COVID19 requiring off-label drugs were identified through a name list generated from the EMR and screened for ADR. Medications that were used in COVID-19 patients during the study period were chloroquine, hydroxychloroquine, lopinavir/ritonavir, atazanavir/ ritonavir, ribavirin, interferon beta- $1 \mathrm{~b}$, tocilizumab or favipiravir.

This study was registered with the National Medical Research Register and was approved by the institutional review boards of the Medical Research Ethics Committee of the Ministry of Health, Malaysia (NMRR-201120-55048 (IIR)).

Table 1 Clinical staging of syndrome associated with COVID-19 [11]

\begin{tabular}{ll}
\hline Clinical stage & Disease progression \\
\hline 1 & Asymptomatic \\
2 & Symptomatic, no pneumonia \\
3 & Symptomatic, pneumonia \\
4 & Symptomatic, pneumonia, requiring sup- \\
& plemental oxygen \\
5 & Critically ill with multi-organ involvement
\end{tabular}

Adapted from Ministry of Health, Malaysia 


\section{Active monitoring by investigators}

A trigger tool (Table 2) consisting of laboratory parameters was prepared as per the definitions from previous guidelines or journals. Meanwhile, adverse events that cannot be defined by laboratory values were matched with adverse events listed in the registered product inserts to identify ADR.

Retrospective chart review was conducted by the investigators trained in pharmacovigilance, covering medical records on discharge summary, procedure notes, progress notes and laboratory data. Actions to minimise misclassification bias include screening medical records in a standardised manner and counterchecking detected ADR by another team member.

\section{Data collection}

Patients' characteristics (diagnosis, sex, age, one or more comorbidities and history of drug allergy), medications for COVID-19 and laboratory results, were documented with a case report form. History of drug allergy can be retrieved from the EMR in the form of free text entry in the progress note. Evaluation of ADR was done when the trigger item or adverse event was detected, with the suspected causative drug, time of onset, treatment of ADR and the clinical outcome being recorded.

\section{Causality assessment}

The causality assessment of all suspected ADR was completed using the World Health Organization-Uppsala Monitoring Centre (WHO-UMC) system [19]. The relationship between the detected ADR and drugs was categorised as certain, probable, possible, unlikely, unclassified/conditional, or unassessable/unclassifiable, and only ADR cases categorised as certain, probable and possible were further analysed.
The seriousness of the ADR was ranked using the International Conference on Harmonization (ICH) E2A guideline (ICH E2A Clinical Safety Data Management: Definitions and Standards for Expedited Reporting). As defined by the guideline, a serious event or reaction is any untoward medical occurrence that at any dose: "(1) resulted in death; (2) is life-threatening; (3) required hospitalisation or resulted in prolongation of existing hospitalisation; (4) resulted in persistent or significant disability/incapacity, or (5) caused congenital anomaly/ birth defect or medically important event or reaction that required medical/surgical intervention to prevent serious outcome" [20].

The clinical outcome indicators of ADR were recovered fully, recovering, not recovered, unknown, or fatal. The ADR was considered clinically cured with the disappearance of symptoms or recovery of the laboratory indexes to normal values. Patients were followed until recovery or discharge, whichever earlier, to determine the clinical outcome.

\section{ADR reporting by healthcare providers}

A separate manual reporting of ADR was completed by the doctors and pharmacists in the facility. These ADR reports were documented in the case bank and submitted to NPRA, and matched with the ADR cases identified in the study to determine the rate of ADR reporting.

$$
\begin{aligned}
& \text { Reporting rate } \\
& =\frac{\text { Number of ADR cases reported by healthcare providers }}{\text { Total number of ADR cases identified in the study }} \times 100 \%
\end{aligned}
$$

\section{Data analysis}

Data collected were analysed using the statistical software Statistical Package for the Social Sciences (SPSS)

\begin{tabular}{|c|c|}
\hline Trigger items & Explanation \\
\hline Exceeds 500 ms or there has been an increase of $\geq 60$ ms compared with the pre-drug baseline value [12] & Drug-induced QT prolongation \\
\hline $\begin{array}{l}\text { Alanine aminotransferase (ALT) } \geq 5 \times \text { or alkaline phosphatase }(A L P) \geq 2 \times \text { and total bilirubin }(T B L) \geq 2 \times \text { upper limit } \\
\text { of normal (ULN) }[13]\end{array}$ & Drug-induced liver injury \\
\hline $\begin{array}{l}\text { Baseline }<180 \mathrm{umol} / \mathrm{L}: 50 \% \text { increment from baseline or minimum increment by } 40 \mathrm{umol} / \mathrm{L} \text {; baseline }>180 \mathrm{umol} / \mathrm{L} \text { : } \\
\text { Minimum increment by } 90 \text { umol/L. Note: Drug exposure must be } 24 \mathrm{~h} \text { preceding the event [14] }\end{array}$ & Drug-induced acute kidney injury \\
\hline$<50 \times 10^{9}$ platelets $/ L[15]$ & Thrombocytopenia \\
\hline$<1.5 \times 10^{9}$ neutrophils/L [16] & Neutropenia \\
\hline$>6.8 \mathrm{mg} / \mathrm{dL}(404 \mu \mathrm{mol} / \mathrm{L})[17]$ & Hyperuricaemia \\
\hline$<10 \mathrm{~g} / \mathrm{dL}$ haemoglobin [18] & Drug-induced anaemia \\
\hline
\end{tabular}

Table 2 Trigger tool for ADR detection 
Version 24.0. All performed analyses were set as twotailed with a confidence interval of $95 \%$ and $P$ value less than 0.05 was considered statistically significant. Demographic data were analysed using descriptive analysis (frequency and percentage). The association of potential risk factors for ADRs was evaluated using both univariate, i.e. Chi-square test, Mann-Whitney test and simple logistic regression, as well as multivariate analysis with multiple linear regression.

\section{Results}

A total of 1080 patients were included in this study. The characteristics of the participants were summarised in Table 3. There were more ADR cases in older patients and those with comorbidity (both $P<0.001$ ). There were no significant differences in proportions of sex and history of drug allergy between the two groups.

Table 3 Demographics and clinical background of participants $(N=1080)$

\begin{tabular}{|c|c|c|c|}
\hline Variable & $\begin{array}{l}\text { Patients with } \\
\text { ADR }(n=217)\end{array}$ & $\begin{array}{l}\text { Patients } \\
\text { without ADR } \\
(n=863)\end{array}$ & $P$ value \\
\hline Age (mean $\pm S D$ in years) & $47.96 \pm 16.50$ & $40.07 \pm 16.51$ & $<0.001^{\dagger}$ \\
\hline \multicolumn{4}{|l|}{ Sex } \\
\hline Male & $137(63.1 \%)$ & $593(68.7 \%)$ & \multirow[t]{2}{*}{$0.116^{\ddagger}$} \\
\hline Female & $80(36.9 \%)$ & $270(31.3 \%)$ & \\
\hline \multicolumn{4}{|l|}{ History of drug allergy } \\
\hline Yes & $5(2.3 \%)$ & $26(3.0 \%)$ & \multirow[t]{2}{*}{$0.576^{\ddagger}$} \\
\hline No & $212(97.7 \%)$ & 837 (97.0\%) & \\
\hline \multicolumn{4}{|l|}{ Presence of comorbidity } \\
\hline Yes & $117(53.9 \%)$ & $294(34.1 \%)$ & \multirow[t]{2}{*}{$<0.001^{\ddagger}$} \\
\hline No & $100(46.1 \%)$ & $569(65.9 \%)$ & \\
\hline \multicolumn{4}{|l|}{ COVID-19 category } \\
\hline $\begin{array}{l}\text { Patient under investi- } \\
\text { gation }\end{array}$ & $9(4.1 \%)$ & $80(9.3 \%)$ & \\
\hline Stage 1 & $1(0.5 \%)$ & $35(4.1 \%)$ & \\
\hline Stage 2 & $27(12.4 \%)$ & $357(41.4 \%)$ & \\
\hline Stage 3 & $85(39.1 \%)$ & $311(36.0 \%)$ & \\
\hline Stage 4 & $79(36.4 \%)$ & $58(6.7 \%)$ & \\
\hline Stage 5 & $16(7.4 \%)$ & $22(2.5 \%)$ & \\
\hline \multicolumn{4}{|c|}{ Number of COVID-19 drug(s) } \\
\hline 1 & $51(23.5 \%)$ & $704(81.6 \%)$ & \\
\hline 2 & $96(44.2 \%)$ & $115(13.3 \%)$ & \\
\hline 3 & $46(21.2 \%)$ & $30(3.5 \%)$ & \\
\hline 4 and 5 & $24(11.1 \%)$ & $14(1.6 \%)$ & \\
\hline
\end{tabular}

Data are $n(\%)$ or mean ( \pm SD)

${ }^{\dagger}$ Analysed with Mann-Whitney $U$ test

${ }^{\ddagger}$ Analysed with Chi-square $\left(X^{2}\right)$ test

\section{Classifications of ADRs}

The adverse events were categorised according to system organ class (SOC) using WHO-Adverse Reaction Terminology (WHO-ART), as listed in Table 4. The most common ADRs detected were gastrointestinal disorders (43.5\%), followed by hepatobiliary disorders $(36.1 \%)$ and cardiac disorders (16.2\%).

\section{Drugs used in COVID-19 and ADR}

Almost all patients (98\%) were started on hydroxychloroquine. Nevertheless, ADRs were most commonly detected in atazanavir (52.7\%), followed by chloroquine $(36.8 \%)$ and lopinavir/ritonavir (34.6\%), as seen in Table 5. The ADRs detected were classified as probable or possible. Most patients fully recovered from the effects of ADR, while the rest showed signs of recovering prior to discharge. No serious ADR was identified from all cases.

Among 217 patients who experienced ADR, drugrelated adverse reactions were highest (44.2\%) in those started on two COVID-19 drugs (Table 3). The pairs of suspected drug with the highest rate of ADR were atazanavir-hydroxychloroquine (25.3\%) and lopinavir/ritonavir-hydroxychloroquine (15.7\%) (Table 6). The most common ADRs among these pairs were hyperbilirubinaemia (6.5\%) and diarrhoea (8.3\%), respectively.

When used individually, the most common ADR detected was hyperbilirubinaemia (37.8\%) for atazanavir and diarrhoea (21.2\%) for lopinavir/ritonavir. Diarrhoea (25.4\%) and QT prolongation (14.3\%) were the most frequently detected ADR for hydroxychloroquine.

\section{Comorbidities and ADR}

The incidence of ADR was higher in patients with one or more comorbidities $(P<0.001)$. Significant difference in incidences of ADR were detected in patients with chronic kidney disease (50\%), cardiovascular diseases (39.7\%), hypertension (30.5\%) and diabetes mellitus (29.9\%) $(P<0.05)$, as compared to those without these comorbidities (Table 7).

\section{Risk factors of ADR}

Using univariate analysis, factors that were associated with the occurrence of ADR include age, presence of comorbidity, patients diagnosed with COVID-19 stage 3 to 5 and number of COVID-19 drugs (Table 8). With every increment in age, the odds of experiencing ADR increases by $3 \%$ (crude odds ratio $[\mathrm{OR}]=1.03, P<0.05$ ).

In multivariate analysis, the independent risk factors for the occurrence of ADR were female (adjusted OR: 1.53; 95\% CI 1.06-2.20; $P=0.02$ ), patients diagnosed with COVID-19 stage 3 (adjusted OR: 2.58; 95\% CI 1.205.55; $P=0.015$ ) and stage 4 (adjusted OR: $4.17 ; 95 \% \mathrm{CI}$ $1.79-9.73 ; P=0.001)$ and number of COVID-19 drugs 
Table 4 Classification of ADR $(n=246)$

\begin{tabular}{|c|c|c|c|c|}
\hline \multirow[t]{2}{*}{ ADR according to SOC } & \multirow[t]{2}{*}{ Incidence of ADR } & \multicolumn{3}{|l|}{ Time to onset } \\
\hline & & Acute (within $60 \mathrm{~min}$ ) & Subacute (1 to $24 \mathrm{~h}$ ) & Latent (after 2 days) \\
\hline \multicolumn{5}{|l|}{ Blood and lymphatic system disorders } \\
\hline Anaemia & $2(0.8 \%)$ & 0 & 1 & 1 \\
\hline \multicolumn{5}{|l|}{ Cardiac disorders } \\
\hline QT prolongation & $34(13.8 \%)$ & 0 & 9 & 25 \\
\hline Bradycardia & $4(1.6 \%)$ & 0 & 1 & 3 \\
\hline ST elevation & $1(0.4 \%)$ & 0 & 0 & 1 \\
\hline Palpitation & $1(0.4 \%)$ & 0 & 0 & 1 \\
\hline \multicolumn{5}{|l|}{ Gastrointestinal disorders } \\
\hline Diarrhoea & $76(30.9 \%)$ & 0 & 49 & 27 \\
\hline Nausea and vomiting & $27(11.0 \%)$ & 1 & 7 & 19 \\
\hline Abdominal pain & $4(1.6 \%)$ & 0 & 2 & 2 \\
\hline \multicolumn{5}{|l|}{ Hepatobiliary disorders } \\
\hline Hyperbilirubinaemia (without jaundice) & $77(31.3 \%)$ & 0 & 17 & 60 \\
\hline Elevated liver transaminases & $6(2.4 \%)$ & 0 & 0 & 6 \\
\hline Hyperbilirubinaemia (with jaundice) & $5(2.0 \%)$ & 0 & 3 & 2 \\
\hline Elevated alkaline phosphatase & $1(0.4 \%)$ & 0 & 0 & 1 \\
\hline \multicolumn{5}{|l|}{ Nervous system disorders } \\
\hline Giddiness & $3(1.2 \%)$ & 1 & 0 & 2 \\
\hline Headache & $1(0.4 \%)$ & 0 & 1 & 0 \\
\hline \multicolumn{5}{|l|}{ Renal and urinary disorders } \\
\hline Acute kidney injury & $2(0.8 \%)$ & 0 & 1 & 1 \\
\hline \multicolumn{5}{|l|}{ Skin and subcutaneous tissue disorders } \\
\hline Rash & $2(0.8 \%)$ & 0 & 1 & 1 \\
\hline
\end{tabular}

Incidence of ADR is reported as $n(\%)$, where $\%$ is calculated by number of ADR/n

Table 5 Suspected drug, ADR, outcome and causality

\begin{tabular}{|c|c|c|c|c|c|c|}
\hline \multirow[t]{2}{*}{ Suspected drugs } & \multirow{2}{*}{$\begin{array}{l}\text { Patient on } \\
\text { treatment }\end{array}$} & \multirow[t]{2}{*}{ ADR } & \multicolumn{2}{|l|}{ Outcome } & \multicolumn{2}{|l|}{ Causality $^{a}$} \\
\hline & & & Recovered & Recovering & Probable & Possible \\
\hline Atazanavir & 167 & $88(52.7 \%)$ & 57 & 29 & 57 & 29 \\
\hline Chloroquine & 19 & $7(36.8 \%)$ & 7 & 0 & 0 & 7 \\
\hline Lopinavir/ritonavir & 214 & 78 (36.4\%) & 75 & 3 & 18 & 60 \\
\hline Ribavirin & 7 & $1(14.3 \%)$ & 1 & 0 & 1 & 0 \\
\hline Hydroxychloroquine & 1035 & $118(11.4 \%)$ & 107 & 11 & 22 & 96 \\
\hline Interferon beta-1b & 91 & $3(4.4 \%)$ & 3 & 0 & 0 & 3 \\
\hline Tocilizumab & 8 & 0 & 0 & 0 & 0 & 0 \\
\hline Favipiravir & 6 & 0 & 0 & 0 & 0 & 0 \\
\hline
\end{tabular}

ADR is reported as $n$ (\%), where \% is calculated by taking ADR/patient on treatment

${ }^{\text {a }}$ No ADR cases were classified as certain

(adjusted OR: 3.34; 95\% CI 2.51-4.44; $P<0.001$ ). Age, presence of comorbidity and diagnosis of COVID-19 stage 5 were not independent risk factors when analysed with multivariate analysis.

\section{Reporting rate of ADR by healthcare professionals}

Among 246 ADR cases detected within the sample, only 49 cases $(19.9 \%)$ were manually reported, in which 48 cases of the ADR reports were submitted by pharmacists, and one case was submitted by doctor. The most 
Table 6 Incidence of ADR in different drug-pair combinations

\begin{tabular}{lc}
\hline COVID-19 drug pair & ADR \\
\hline Atazanavir-hydroxychloroquine & $55(25.3 \%)$ \\
Lopinavir/ritonavir-hydroxychloroquine & $34(15.7 \%)$ \\
Lopinavir/ritonavir-interferon beta-1b & $5(2.3 \%)$ \\
Atazanavir-favipiravir & $1(0.5 \%)$ \\
Lopinavir/ritonavir-chloroquine & $1(0.5 \%)$
\end{tabular}

ADR is reported as $n(\%)$, where \% is calculated by taking ADR/patient with ADR

Table 7 Comorbidity and ADR

\begin{tabular}{lccr}
\hline Comorbidity & $\begin{array}{l}\text { Number } \\
\text { of } \\
\text { patients }\end{array}$ & Patients with ADR & P value $^{\#}$ \\
\hline Cancer & 4 & $3(75.0 \%)$ & 0.006 \\
Obesity & 7 & $5(71.4 \%)$ & 0.001 \\
Chronic kidney disease & 38 & $19(50.0 \%)$ & $<0.001$ \\
Cardiovascular diseases & 58 & $23(39.7 \%)$ & $<0.001$ \\
Hypertension & 249 & $75(30.1 \%)$ & $<0.001$ \\
Diabetes mellitus & 157 & $46(29.3 \%)$ & 0.002 \\
Chronic obstructive lung & 4 & $1(25.0 \%)$ & 0.814 \\
disease & 47 & $10(21.3 \%)$ & 0.862 \\
Asthma & 47 &
\end{tabular}

Patients with ADR are reported as $n(\%)$, where \% is calculated by patients with ADR/number of patients

\# Analysed with Chi-square $\left(X^{2}\right)$ test

commonly reported ADRs were hyperbilirubinaemia (65.3\%) and QT prolongation (28.6\%), with the main suspected drug being atazanavir and hydroxychloroquine, respectively. There were no ADR reports received for gastrointestinal symptoms, despite it contributing to the most number of ADR cases detected.

\section{Discussion}

Around 20\% of hospitalised patients experienced ADR while receiving treatment for COVID-19 based on the findings of this study. In China, Sun et al. [6] reported a higher ADR incidence rate of $37.8 \%$ among their COVID19 patients. A systematic review of 29 studies had published that the prevalence of ADR among inpatients (non-COVID-19 related) ranged from 1.6\% to 41.4\% [21]. In summary, ADR appears to be an event that occurs with drug use irrespective of indication. The predominant ADRs detected in this study were gastrointestinal and liver-related disorders, in agreement with the results by Sun et al. [6].

The ADRs detected in this study were classified as probable or possible. In practice, few reactions are considered as "certain" due to the presence of confounding factors in most cases, including the underlying diseases or concomitant drugs, that has to be considered during the evaluation of a causal relationship between a drug and an ADR [19, 22]. Meanwhile, the causality category "probable" indicates that the ADR is "unlikely to be attributed to the disease or other drugs", whereas "possible" suggests that the ADR "could be explained by the disease or other drugs" [19]. No serious ADR was detected from this study, possibly due to timely discontinuation of medication by the treating physicians.

Risk factors for ADR determined in this study using univariate analysis include age, presence of comorbidity, diagnosis of COVID-19 stage 3 to 5 , and the number of COVID-19 drugs. The independent risk factors of ADR identified with multivariate analysis were female, diagnosis of COVID-19 stage 3 and stage 4, and the number of COVID-19 drugs.

It has been established that the elderly population is more prone to developing ADRs [23]. Our study has shown that the risk of ADR increases by $3 \%$ with each increasing year in age. The older patients could be affected due to the presence of chronic disease, polypharmacy and age-related physiological changes that may alter the drug's pharmacokinetics and pharmacodynamics [24]. On a related note, patients with comorbidity are found to have a 2.26-fold risk of experiencing ADR compared to patients with no known medical illnesses, possibly due to the complex interactions between multiple drugs and disease states [25].

Several studies had identified the female gender as one of the potential risk factors of experiencing ADR [23, $25,26]$. Our study reported a 1.53 -fold risk in females to experience ADR than males, which corresponds to current literature [23, 25, 26]. Postulated factors such as differences in circulating hormonal levels, having more prescription drugs, and a higher dose used in relation to their body weight were used to explain this phenomenon [26].

The recommended treatment from Guidelines on COVID-19 Management in Malaysia (as of 24 March 2020), at the point of data collection, was hydroxychloroquine in patients with COVID-19 stage 2, with the addition of protease inhibitors (atazanavir or lopinavir/ ritonavir) in stage 3 (with warning signs) as well as stage 4. [27].

Patients who developed ADR were mostly diagnosed with COVID-19 stage 3 (39.3\%, adjusted OR: 2.62; $95 \%$ CI $1.22-5.63 ; P=0.014)$ or stage $4(36.1 \%$, adjusted OR: 4.16; 95\% CI 1.78-9.71; $P=0.001)$. The use of these protease inhibitors could have contributed to most of the ADRs observed in this group of patients. Hyperbilirubinaemia is a well-documented ADR of atazanavir, whereas diarrhoea is a common ADR for lopinavir/ritonavir [28]. This study demonstrated that off-label use of medications 
Table 8 Univariate and multivariate model of variables associated with ADR

\begin{tabular}{|c|c|c|c|c|}
\hline Variable & Crude OR $(95 \% \mathrm{Cl})$ & $P$ value & Adjusted OR $(95 \% \mathrm{Cl})^{\mathrm{a}}$ & $P$ value \\
\hline \multicolumn{5}{|l|}{ Demographics } \\
\hline Age (mean $\pm S D$ in years) & $1.03(1.02,1.04)$ & $<0.001$ & - & - \\
\hline \multicolumn{5}{|l|}{ Sex } \\
\hline Male & 1 & - & 1 & - \\
\hline Female & $1.28(0.94,1.75)$ & 0.117 & $1.53(1.06,2.20)$ & 0.024 \\
\hline \multicolumn{5}{|l|}{ Clinical background } \\
\hline \multicolumn{5}{|l|}{ History of drug allergy } \\
\hline Yes & $0.76(0.29,2.00)$ & 0.577 & - & - \\
\hline No & 1 & - & 1 & - \\
\hline \multicolumn{5}{|l|}{ Presence of comorbidity } \\
\hline Yes & $2.26(1.68,3.06)$ & $<0.001$ & - & - \\
\hline No & 1 & - & 1 & - \\
\hline \multicolumn{5}{|l|}{ COVID-19 category } \\
\hline Patient under investigation & 1 & - & 1 & - \\
\hline Stage 1 & $0.25(0.03,2.08)$ & 0.202 & - & - \\
\hline Stage 2 & $0.67(0.30,1.48)$ & 0.319 & - & - \\
\hline Stage 3 & $2.45(1.18,5.07)$ & 0.016 & $2.58(1.20,5.55)$ & 0.015 \\
\hline Stage 4 & $12.11(5.62,26.10)$ & $<0.001$ & $4.17(1.79,9.73)$ & 0.001 \\
\hline Stage 5 & $6.47(2.52,16.60)$ & $<0.001$ & - & - \\
\hline Number of COVID-19 drug(s) & $3.94(3.20,4.85)$ & $<0.001$ & $3.34(2.51,4.44)$ & $<0.001$ \\
\hline
\end{tabular}

${ }^{a}$ Forward and backward LR applied. Hosmer and Lemeshow $=0.121$. Classification table $=83.2$. No multicollinearity was detected. ROC $=0.83(0.79,0.86 ; P$ value $\leq 0.001)$. Only variables with $P$ value $<0.05$ were mentioned in the AOR

in COVID-19 patients showed similar safety profile when used as per FDA-approved indications [29-31].

Multivariate analysis revealed that the risk of ADR was increased by 3.34 times with every addition of one COVID-19 drug to the treatment regime. Despite numerous studies investigating the effect of the number of drugs on ADR occurrence, the mechanism remains unestablished. It was proposed that drug-drug interactions could have contributed to most ADR, which arose from pharmacokinetic or pharmacodynamic interactions $[8,23]$. Examples of pharmacokinetic interactions include induction or inhibition of metabolising enzymes and displacement of a drug from plasma protein binding sites; on the other hand, pharmacodynamic interactions involve additive or antagonistic pharmacological effects [8].

ADR reporting is defined as identify, quantify, evaluate and prevent risk related to the use of marketed drugs [32]. All healthcare workers are responsible for documenting and reporting clinically important ADR to the national pharmacovigilance centre [33]. However, voluntary reporting may lead to substantial underreporting of ADR [33]. During the study period, our facility's reporting rate was $19.9 \%$, which was translated to an underreporting rate of $80.1 \%$. A systematic review investigated the extent of underreporting of an ADR to spontaneous reporting systems in hospitals and general practices across 37 studies from 12 countries and found that the median underreporting rate was $94 \%$ (interquartile range 82-98\%) [10].

Common reasons for underreporting among healthcare workers were inexperience (reporting only serious and unexpected ADR), insecurity (notification made only when damage is certain), indifference (postponing notification of damage due to various excuses) and lack of training in pharmacovigilance (unfamiliar with procedures to report ADR) [34]. These factors are consistent with the observations made in our facility, as only severe ADR reports (e.g. hyperbilirubinaemia and QT prolongation) were received.

Almost all (98\%) of ADR reports were submitted by the pharmacists during the study period. This corresponds to the local nationwide ADR reporting pattern, where majority of the ADR reports (68.1\%) were submitted by pharmacists and only $16.5 \%$ were submitted by doctors in 2018 [35]. A similar trend was observed where pharmacists were the highest notifiers for ADR cases in other parts of the world, implicating that pharmacists may have greater engagement in pharmacovigilance issues [22]. Hence, continuous education for other healthcare professionals is much needed to encourage adherence to ADR surveillance [22, 34]. 
This study provided an overview on the incidence of ADR for the off-label use of medications among COVID19 patients during the early days of the pandemic in a Malaysian COVID-19 referral hospital. It was worth noting that the WHO clinical management interim guidance (as of 13 March 2020) states "there is no current evidence to recommend any specific anti-COVID-19 treatment for patients with confirmed COVID-19", and advises that "investigational anti-COVID-19 therapeutics should be used only in approved, randomised, controlled trials" [36].

The latest WHO Therapeutics and COVID-19: Living Guideline (released 31 March 2021) recommends against administering hydroxychloroquine, chloroquine and lopinavir/ritonavir for the treatment of COVID-19 due to a lack of evidence in improving patient outcome, coupled with the risk of increased adverse events [37]. However, our findings suggest a similar safety profile when prescribed for FDA-approved indications. Only favipiravir, interferon beta- $1 \mathrm{~b}$ and tocilizumab are currently in use in our facility.

There are some limitations to this study. As patients were enrolled for retrospective chart review using convenience sampling, this may result in skewed patient demographics. Although measures to reduce misclassification bias were implemented, it may be impossible to completely eliminate this error. The causal relationship between the drug and ADR may be influenced by other confounding factors, especially in nonspecific complaints (eg. gastrointestinal symptoms), despite only taking into account related adverse events that occurred after drug use. A lack in a comparator group also makes it difficult to rule out the interference caused by COVID-19 infection.

The interpretation of the study may also be limited by the minimal usage of favipiravir and tocilizumab during the study period, resulting in poor representation of ADR cases for these medications. Thus, further investigations may be necessary to determine the rate of ADR associated with favipiravir and tocilizumab.

\section{Conclusion}

The repurposed medications for COVID-19 management suggest a similar safety profile when compared to the usage of medications prescribed for FDA-approved indications. This present study found that $20.1 \%$ of patients experienced ADR from off-label drugs used in COVID19 management. The ADRs detected mostly affect the gastrointestinal, hepatobiliary and cardiovascular systems. Female, diagnosis of COVID-19 stage 3 and stage 4 , and the number of COVID-19 drugs were identified as independent risk factors of ADR. Regardless, low reporting rate among healthcare professionals remains an issue to be tackled to provide a more complete and accurate representation of ADR cases. Given the uncertainty surrounding COVID-19, more research is warranted in ADR surveillance to maximise patient safety.

\begin{abstract}
Abbreviations
ADR: Adverse drug reaction; ALP: Alkaline phosphatase; ALT: Alanine aminotransferase; COVID-19: Coronavirus disease 2019; EMR: Electronic medical record; FDA: Food and Drug Administration; ICH: International Conference on Harmonization; MERS: Middle-East respiratory syndrome; NPRA: National Pharmaceutical Regulatory Agency; OR: Odds ratio; SARS: Severe acute respiratory syndrome; SOC: System organ class; SPSS: Statistical Package for the Social Sciences; TBL: Total bilirubin; ULN: Upper limit of normal; WHO: World Health Organization; WHO-ART: World Health Organization-Adverse Reaction Terminology; WHO-UMC: World Health Organization-Uppsala Monitoring Center.
\end{abstract}

\section{Acknowledgements}

We would like to thank the Director General of Health Malaysia for his permission to publish this article.

\section{Authors' contributions}

LYY designed the study, collected data, and was a major contributor in data analysis as well as manuscript writing and revision. AASY was involved in study design, data collection and analysis, and manuscript editing. NMA and ALM contributed in data collection. AO conceptualised the study. All authors read and approved the final manuscript.

Funding

The study was self-funded.

\section{Availability of data and materials}

The datasets used and/or analysed during the current study are available from the corresponding author on reasonable request.

\section{Declarations}

Ethics approval and consent to participate

The study was registered with the National Medical Research Register and was approved by the institutional review boards of the Medical Research Ethics Committee of Ministry of Health Malaysia (NMRR-20-1120-55048 (IIR)).

\section{Consent for publication}

All authors have given verbal consent for publication.

Competing interests

The authors declare that they have no competing interests.

Received: 21 January 2021 Accepted: 2 October 2021

Published online: 25 October 2021

References

1. World Health Organisation (WHO). Coronavirus disease (COVID-19) pandemic. https://www.who.int/emergencies/diseases/novel-coron avirus-2019. Accessed on 16 May 2020.

2. Sanders JM, Monogue ML, Jodlowski TZ, Cutrell JB. Pharmacologic treatments for Coronavirus disease 2019 (COVID-19): a review. JAMA. 2020;323(18):1824-36. https://doi.org/10.1001/jama.2020.6019.

3. Equale T, Buckeridge DL, Verma A, et al. Association of off-label drug use and adverse drug events in an adult population. JAMA Intern Med. 2016;176(1):55-63. https://doi.org/10.1001/jamainternmed.2015.6058.

4. Huang M, Li M, Xiao F, et al. Preliminary evidence from a multicenter prospective observational study of the safety and efficacy of chloroquine for the treatment of COVID-19. Natl Sci Rev. 2020;7(9):1428-36. https:// doi.org/10.1093/nsr/nwaa113. 
5. Gérard A, Romani S, Fresse A, et al. "Off-label" use of hydroxychloroquine, azithromycin, lopinavir-ritonavir and chloroquine in COVID-19: a survey of cardiac adverse drug reactions by the French Network of Pharmacovigilance Centers. Therapies. 2020;75(4):371-9. https://doi.org/10.1016/j. therap.2020.05.002

6. Sun J, Deng $X$, Chen $X$, et al. Incidence of adverse drug reactions in COVID-19 patients in China: an active monitoring study by hospital pharmacovigilance system. Clin Pharmacol Ther. 2020;108(4):791-7. https:// doi.org/10.1002/cpt.1866.

7. National Pharmaceutical Regulatory Agency. Malaysian pharmacovigilance guidelines. 2nd edition. https://www.npra.gov.my/images/Guide lines_Central/Guidelines_on_Reporting_and_Monitoring\%20_(MADRA C)/Malaysian_Pharmacovigilance_Guidelines_2nd_Edition_2016.pdf. Accessed 20 Apr 2021.

8. Alomar MJ. Factors affecting the development of adverse drug reactions. Saudi Pharm J. 2014;22(2):83-94. https://doi.org/10.1016/j.jsps.2013.02. 003.

9. Schatz SN, Weber RJ. Adverse drug reactions. In: Murphy JE, Lee MW, editors. PSAP 2015 Book 2 CNS/pharmacy practice: pharmacotherapy selfassessment program. New York: American College of Clinical Pharmacy; 2015. p. 5-21.

10. Hazell L, Shakir SA. Under-reporting of adverse drug reactions. Drug Saf. 2006;29:385-96. https://doi.org/10.2165/00002018-200629050-00003.

11. Ministry of Health, Malaysia. Clinical Management of Confirmed COVID19 Case in Adult (Annex 2E). Version 24 March 2021.

12. Drew BJ, Ackerman MJ, Funk M, et al. Prevention of Torsade de Pointes in hospital settings. J Am Coll Cardiol. 2010;55(9):934-47. https://doi.org/10. 1161/CIRCULATIONAHA.109.192704.

13 Association E. EASL clinical practice guidelines: drug-induced liver injury. J Hepatol. 2019;70(6):1222-61. https://doi.org/10.1016/j.jhep.2019.02.014.

14. Naughton CA. Drug-induced nephrotoxicity. Am Fam Physician. 2008;78(6):743-50. https://doi.org/10.1001/jamainternmed.2015.6058.

15. Visentin GP, Chao YL. Drug Induced Thrombocytopenia. Hematol Oncol Clin N Am. 2007;21(4):685-96, vi. https://doi.org/10.1016/j.hoc.2007.06. 005.

16. Curtis BR. Non-chemotherapy drug-induced neutropenia: key points to manage the challenges. Hematol Am Soc Hematol Educ Progr. 2017;1:187-93. https://doi.org/10.1182/asheducation-2017.1.187.

17. Salem CB, Slim R, Fathallah N, Hmouda H. Drug-induced hyperuricemia and gout. Rheumatology. 2016;56(5):679-88. https://doi.org/10.1093/ rheumatology/kew293.

18. Nomura $\mathrm{H}$, Tanimoto $\mathrm{H}$, Kajiwara $\mathrm{E}$, et al. Factors contributing to ribavirininduced anemia. J Gastroenterol Hepatol. 2004;19(11):1312-7. https://doi. org/10.1111/j.1440-1746.2004.03459.x.

19. World Health Organization-Uppsala Monitoring Centre (WHO-UMC). The use of the WHO-UMC system for standardised case causality assessment. https://www.who.int/medicines/areas/quality_safety/safety_efficacy/ WHOcausality_assessment.pdf. Accessed 22 Apr 2021.

20. ICH Steering Committee. Clinical safety data management: definitions and standards for expedited reporting E2A. https://www.crc.gov.my/wpcontent/uploads/documents/ICH\%20E2A.pdf. Accessed 22 Apr 2021.

21. Cano FG, Rozenfeld S. Adverse drug events in hospitals: a systematic review. Cad Saude Publica. 2009;25(suppl 3):S360-72. https://doi.org/10. 1590/s0102-311×2009001500003.

22. Melo JRR, Duarte EC, de Moraes MV, et al. Adverse drug reactions in patients with COVID-19 in Brazil: analysis of spontaneous notifications of the Brazilian pharmacovigilance system. Cad Saude Publica. 2021;37(1):e00245820.

23. Davies EC, Green CF, Taylor S, et al. Adverse drug reactions in hospital in-patients: a prospective analysis of 3695 patient-episodes. PLOS ONE. 2009:4(2):e4439. https://doi.org/10.1371/journal.pone.0004439.

24. Dupouy J, Moulis G, Tubery M, et al. Which adverse events are related to health care during hospitalization in elderly inpatients? Int J Med Sci. 2013;10(9):1224-30. https://doi.org/10.7150/ijms.6640.

25. Giardina C, Cutroneo PM, Mocciaro E, et al. Adverse drug reactions in hospitalized patients: results of the FORWARD (Facilitation of Reporting in Hospital Ward) study. Front Pharmacol. 2018;9:350. https://doi.org/10. 3389/fphar.2018.00350

26. Zopf Y, Rabe C, Neubert A, Hahn EG, Dormann H. Risk factors associated with adverse drug reactions following hospital admission. Drug Saf. 2008;31(9):789-98. https://doi.org/10.2165/00002018-200831090-00007.

27. Muñoz-Torrero JF, Barquilla P, Velasco R, et al. Adverse drug reactions in internal medicine units and associated risk factors. Eur J Clin Pharmacol. 2010;66(12):1257-64. https://doi.org/10.1007/s00228-010-0866-6.

28. Ministry of Health, Malaysia. Malaysian consensus guidelines on antiretroviral therapy. https://www.researchgate.net/publication/319101215_ Malaysian_Consensus_Guidelines_on_Antiretroviral_Therapy_2017_ MINISTRY_OF_HEALTH_MALAYSIA. Accessed 20 Apr 2021.

29. VigiAccess. http://www.vigiaccess.org/. Accessed 22 Apr 2021.

30. Reyataz ${ }^{\circledR}$ Product Insert. Revised October 2011. https://www.accessdata. fda.gov/drugsatfda_docs/label/2011/021567s026lbl.pdf. Accessed 22 Apr 2021.

31. Kaletra ${ }^{\circledR}$ Product Insert. Revised November 2016. https://www.acces sdata.fda.gov/drugsatfda_docs/label/2016/021251s052_021906s046lbl. pdf. Accessed 22 Apr 2021.

32. Haider N, Mazhar F. Factors associated with underreporting of adverse drug reactions by nurses: a narrative literature review. Saudi J Health Sci. 2017;6(2):71-6.

33. Hofer-Dueckelmann C, Prinz E, Beindl W, et al. Adverse drug reactions (ADRs) associated with hospital admissions-elderly female patients are at highest risk. Int J Clin Pharmacol Ther. 2011;49(10):577-86. https://doi. org/10.5414/cp201514

34. Varallo FR, Guimarães SOP, Abjaude SAR, Mastroianni PC. Causes for the underreporting of adverse drug events by health professionals: a systematic review. Rev Esc Enferm USP. 2014;48(4):739-47. https://doi.org/10. 1590/s0080-623420140000400023.

35. National Pharmaceutical Regulatory Agency. 2018 Annual report National Centre for adverse drug reactions monitoring. https://npra.gov.my/easya rticles/images/users/1108/Annual\%20Report/AR2018.pdf. Accessed 22 Apr 2021.

36. World Health Organization. Clinical management of severe acute respiratory infection (SARI)|'when COVID-19 disease is suspected: interim guidance, 13 March 2020. https://apps.who.int/iris/handle/10665/331446.

37. World Health Organization. Therapeutics and COVID-19: living guideline. https://www.who.int/publications/i/item/WHO-2019-nCoV-therapeuti cs-2021.1. Accessed 22 Apr 2021.

\section{Publisher's Note}

Springer Nature remains neutral with regard to jurisdictional claims in published maps and institutional affiliations. 